\title{
CARDIO-PULMONARY DISTURBANCES IN THORACIC SURGERY
}

\author{
Jean-Paul Dechêne, M.D.*
}

DURng the last two years and a half, 243 thoracoplasties, 264 pulmonary resections, and 6 decortications were performed at Laval Hospital, Quebec. As anaesthetist, we observed various cardio-pulmonary disturbances during pre-, per-, and postoperative courses We thought that the analysis of these problems could be highly interesting, and might provide some guidance when surgery is proposed for pulmonary tuberculosis.

During the preoperative period, complete evaluation of pulmonary function, cardiac reserves, and blood volume is imperative. Recent advances in the surgical treatment of diseases of the pulmonary and cardiovascular systems demand a deeper understanding of the function of these systems. Surgical treatment is being currently advocated for patients in whom respiratory and cardiac function are borderlme. These patients' reserves should be fully and accurately evaluated before surgery. According to the classification of Baldwin, Pulmonary function studies may be divided into the mechanical or structural, and the alveolar respiratory or physico-chemical. Mechanical tests consider the lungs as bellows and the tests are either static in type (for vital capacity, inspiratory capacity, tidal air, expiratory reserve, residual capacity, total lung volume) or dynamic (for walking, ventilation, maximum breathug capacity, tumed vital capacity). Alveolar respiratory tests are concerned with the quantity and quality of gaseous exchange at the inspiratory, alveolar, capillary, and tssue levels. They include tests for intra-pulmonary gas mixing, diffusion tests and arterial blood studies.

Until recently, we had to limit our activities to ventilation tests. We are now beginning alveolar exchange studies. Our studies, on 220 patients would indicate that pulmonary tuberculosis reduces pulmonary efficiency. The actual vital capacity was found to be 75 per cent or less of the estimated vital capacity in 191 cases; 87 per cent. The actual maximum breathing capacity was found to be 75 per cent or less of the estimated maximum breathing capacity in 159 cases; 72 per cent.

For the evaluation of cardiac reserves, the venous pressure and circulation time are two very helpful tests. According to $\mathrm{P}$ D White, venous pressure is the criterion of the function of the right ventricle. Normal venous pressure ranges from 2 to $10 \mathrm{~cm}$. of water. The critical level is $20 \mathrm{~cm}$. of water. The clinical value of the circulation time is the estimation of the degree of decompensation in any heart case, especially left ventricular failure. The higher the figure expressing the circulation time, the greater is the degree of decompensation. Venous pressure was taken in 73 patients preoperatively. In 10 patients ( 14 per cent) venous pressure was found to be above $20 \mathrm{~cm} . \mathrm{H}_{2} \mathrm{O} ; 48$ patients ( 66 per cent) had more than $10 \mathrm{~cm} . \mathrm{H}_{2} \mathrm{O} ; 15$ patients (20 per cent) had a normal venous pressure. On the

"Hôpital Laval, Québec, Qué 
other hand, only 3 per cent of our patients showed a prolonged circulation time. We did electrocardiogram tracings on 199 patients. Of these, 160 had normal tracings; 12 patients showed right incomplete bundle branch blocks, which is not too significant, 6 patients had left axis deviation with left heart hypertrophy; 21 patients showed right axis deviation with strain. Most of the patients with right heart hypertrophy had severe pulmonary insufficiency.

Moot's test is an additional good criterion for estimation of cardiac reserves. This test multplies the pulse pressure by 100 and the figure obtained is divided by the diastolic pressure It was done on 73 patients: 30 patients had figures below $40 \mathrm{~mm} \mathrm{Hg}$., the normal being between 40 and $60 \mathrm{~mm}$. $\mathrm{Hg}$.

It has been reported that tuberculous patients often show reduction of blood volume Some clinical signs may help in this field but we like to rely on laboratory tests The dye method using Evan's Blue or P.V.P. has appeared to us to be highly satisfactory. It was used for 65 of our patients. Twenty-four (24) patients showed a blood volume reduction of more than $600 \mathrm{cc}$.

In the light of all the above-mentioned studies, we have been able preoperatively to correct deficiencies and prevent complications as far as this was feasible. Pulmonary insufficiency was treated by respiratory exercises under the supervision of a trained physiotherapist Patients were taught how to breathe and cough Emphysematous patients were given positive pressure and aminophyllin which is mainly helpful when there is an elevation of the venous pressure. Bronchodilators like "Vaponefrin" given in aerosol may be indicated in obstructive endobronchial lesions. Blood volume was restored preoperatively to its normal value.

With a better knowledge of the patient's condition and following the correction of well-known deficiencies, the anaesthesia can be more safely begun. During the operative period, the anaesthetist comes up against the problem of anoxia. Anaesthetic agents are a matter of choice. On the other hand, adequate oxygenation of the patient is imperative. We have found that the prone position on the operatıng table seems to afford a better ventilation than the lateral position. This isolated measure would be inadequate. Endotracheal on endobronchial intubation permits one to delive1 oxygen directly into the tracheobronchial tree under well-controlled conditions. Oxygen can be given under positive pressure which may prove to be very helpful if cardiac arrest occurs. Paradoxical breathing and mediastinal flutter are easlly controlled. Free arrways are at all times available; secretions can be quickly' removed.

The ready removal of secretions is very important when dealing with tuberculous patients where bronchogenic spread may occur. For the surgeon w oo likes to operate in the lateral position, we favour the use of the Carlen's double lumen catheter. This tube completely separates the two lungs. It prevents flooding of the dependent good lung by secretions coming down from the diseased lung. It permits separate aspiration and inflation of each lung. In the prone position, there is good postural drainage of secretion which must come down the trachea as soon as it leaves the respective lung. A simple endotracheal tube permits good oxygenation without danger of spread. Yet the Carlen's double lumen zatheter may also be helpful in the prone position. The bronchus to be sutured can be 
completely isolated from the tracheobronchial tree. This enables the surgeon to close the bronchial stump under better conditions.

Very few of our patients showed respiratory acidosis. Preoperative and endoperatıve $\mathrm{CO}_{2}$ combining power determinations revealed simular figures. There was an increase of 20 volumes per cent in 31 per cent of our cases and of 10 volumes per cent in 12 per cent of this series. In only one instance, we had a blood $\mathrm{Ph}$ at 7.3 , at the end of the operation. Arterial oxygen saturation has been consistently normal. During the operation, blood lost is measured by the weighing of sponges and blood is replaced accordingly. This method has appeared to us to be satisfactory. Postoperative blood volume determinations closely correlated to the preoperative findings.

The thoracic operation is taking place in cardio-pulmonary zones which are the most reflexogenic of the body. Difficulties arisung from vagq-vagal reflexes are either of pulmonary or cardiovascular ongin They include bronchospasm with reduction of tidal air, apnea, a-v block, bradycardia, hypotension, arrythmia, tachy-arrythmia, cardiac asystole. They are more likely to occur in the presence of respiratory acidosis. Ther prevention demands the following measures. Intubation must be performed after good topical anaesthesia of the vocal cords and with the patuent in a fairly deep plane of general anaesthesia. Spreading of ribs stretches intercostal nerves and may induce the above-mentioned difficulties. We routinely block the intercostal nerves as soon as the muscles of the chest wall have been sectioned. We used long-acting agents that may by reducing pain benefit the patient postoperatively. Reflexes by traction on the pulmonary hilum may be reduced by infiltration of the vagus nerve with procaine or by the intravenous injection of atropine. Reflexes from pericardial manipulation may be minimized by the intrapericardial injection of procane. Cardiac arrest is the ultimate effect of anoxia and marked reflex stimulation. If it occurs, the anaesthetist should immediately look for close co.operation with the surgeon and the surgical team. The surgeon immediately performs cardiac massage for adequate curculation. The anaesthetist gives oxygen under positive pressure. Intracardiac use of epinephrine may sometimes be helpful.

If ventricular fibrillation occurs, electric defibrillation should be performed. We have had 12 cases of cardiac arrest. They were all treated by oxygen under positive pressure, cardiac massages, and epinephrme intracardially. Six patients were successfully treated. Six patients did not recover cardiac activity and died.

During the immediate postoperative period of these patients, the anaesthetist is mainly concerned with removal of retained secretions and with the prevention of atelectasis. When the patient leaves the operatıng room, his tracheo-bronchial tree should be completely free of secretions. This freedom must be maintained throughout the sostoperative course. Accumulation of secretions interferes with oxygenation by ronchial plugging and often leads to atelectasis, pneumonitis, or both. Excessive formation of secretions postoperatively can be avoided during the anaesthetic period itself by gentle handling of the tracheo-bronchial tree and by intermittent inflation of the operated lung. We advocate the use of less depressive sedatives like "Demerol," "Levo-dromoran," "Largactil." The patient must be encouraged to cough and breathe deeply. Aerosol may be helpful in mobilizing 
secretions. Position is frequently changed. Intercostal nerve block with a longacting agent is routinely performed: Alcohol solutions rnay be given intravenously. According to Dr. Mary Karp of the Wesley Memorial Hospital, Chicago, the need of narcotics is reduced to 30 to 50 per cent.

We tend to agree with Dr. Karp's opmion. If these measures fail to prevent retention of secretions or atelectasis, tracheo-bronchial aspiration must be immediately performed. Transnasal aspiration may be tried. Broncho-aspiration is often needed. Tracheotomy is sometimes indicated.

Right heart failure sometimes occurs postoperatively. This is to be expected in respiratory borderline pattents and in the aged group of patients. The anaesthetist must be well aware of this complication. The slightest doubt demands the help of a cardıologist.

We have stressed the definite importance of the preoperative evaluation of the thoracic surgical patient. We have also described methods of prevention and treatment of the more serious complications. Finally, extensive investigation and survey have been possible in 53 consecutive cases recently operated on. In this group of patients, we have had no deaths and no serious cardio-pulmonary disturbances. This work has been supported by a Public Health Research grant.

We strongly feel that the great majority of complications can be prevented with a better knowledge of the patient's condition and with proper anaesthetic techniques.

\section{RÉSUMÉ}

Depuis deux ans et demi, 243 thoracoplasties, 264 résections pulmonaires et 6 décortications ont été pratiquées à l'Hôpital Laval de Q̨uébec. Comme anesthésiste, nous avons eu l'occasion d'observer différents troubles cardio-pulmonaires avant, pendant, et après ces interventions. Nous avons pensé qu'une analyse de ces problèmes serait d'un grand intérêt pour les phtysiologistes dans les cas de tuberculose pulmonaire où un traitement chirurgical est indiqué.

A la phase pré-opératoire, l'observation d'un nombre imposant d'opérés thoraciques démontre qu'il est irnpératif de bien évaluer la fonction pulmonaire, les réserves cardiaques et l'état du volume sanguin. A l'aide de ces connaissances, nous avons pu corriger certaines déficiences et à la fois nous étions prêts à solutionner tout problème survenant au cours d'ánesthésie ou dans les suites post-opératoires.

A la période opératơrre proprement dite, nous luttons contre l'anoxie en réalisant chez nos malades l'oxygénation la plus parfaite possible. Nous maintenons le volume sanguin en remplaçant adéquatement le sang perdu et nous combattons les accidents vagaux de l'anesthésie tant respiratoires que cardiovasculaires par tous les moyens mis à notre disposition.

A la période post-opératoire, la rétention de sécrétions ou même l'atélectasie pulmonaire et la décompensation cardiaque sont les principales complications auxquelles l'anesthésiste doit s'attendre et nous vous présentons à la fois le traitement prophylatique et thérapeutique de ces deux grandes complications.

Nous avons démontré l'inportance de l'évaluation pré-opératoire d'un patient en chirurgie thoracique. Nous avons aussi décrit les méthodes préventives et le 
traitement des complications les plus sérieuses. Enfin, grâce à un octroi gouvernemèntal, nous avons pu faure des études cardio-respuratoires chez 53 cas consécutifs, de chirurgie thoracique et parmi ce groupe, nous n'avons enrégistré aucune mortalité et aucune complication cardio-respiratoire sérieuse.

\section{REFERENCES}

1 BeEr, E Geonge Clincal Evaluation of Pulmonary Function Tests. Anesth, \& Analg. 32. 411 (1953).

2 O'Brien, Chardes E. Current Concepts of Pulmonary Function J Am A Nurse Anesth (February, 1954).

3 Bjork, Viking Olov, Carlens, Eric, \& Friberg, Olle Anesthesiology 14. 60 (1953).

4. Forsiree, Nelda Biggins. Problems of the Anesthetist in Intrapleural Surgery J. Am A. Nurse Anesth (February, 1953)

5 Orтол, R H. Carbon Dioxıde Accumulation Anaesthesia 7211 (1953)

6 Raffan, A. W Reflex Cardrac Arrest under Anaesthesia Anaesthesia 9116 (1954).

7 Englisfr, I. C W Selective Bronchial Intubation in Anesthesia for T.aoracic Surgery. Anesth \& Analg. $31 \quad 170$ (1952)

8. LANDis, F B \& WEISEL, Wrison Comparative Study of Fulmonary Loss Thoracoplasty versus Small Resection in Surgery of Tuberculosis J Thoracic Surg 27. 336 (1954).

9. Cole, Francis H \& LougheEd, J C. Blood Loss and its Replacement in Thoracic Surgery J Thoracic Surg. 27. 402 (1954).

10. Hosler, RoBert M Emergency Treatment of Cardiac Arrest J Am A Nurse Anesth (February, 1952)

11. Crandeli, D. Leroy \& Artusio, J. F Cardio-vascular Reflexes during Intrathoracic Surgery. Anesth \& Analg $32 \quad 227$ (1953)

12. Makit, Harry P Pulmonary Physiology Its Significance in Anesthesia for Thoracic Surgery J Am. A Nurse Anesth (November, 1953)

13. Beecher, Henry K. Anesthesia for Thoracic Surgery Spnngfield, Ill . Charles C Thomas (1952).

14.' DechÊNE, J -P \& Hudon, F Contribution of Anaesthesia in Thoracic Surgery for Tuberculosis Patients. Proc Canad Anaesth Soc (1953) 